\title{
Research on a 3D Predator-Prey Evolutionary System in Real Estate Market
}

\author{
Yujing Yang $\mathbb{D}^{1,2}$ and Wenzhe Tang $\mathbb{D} \mathbb{D}^{1,2}$ \\ ${ }^{1}$ Institute of Project Management and Construction Technology, Tsinghua University, Beijing, China \\ ${ }^{2}$ State Key Laboratory of Hydroscience and Engineering, Tsinghua University, Beijing, China
}

Correspondence should be addressed to Wenzhe Tang; twz@mail.tsinghua.edu.cn

Received 11 October 2017; Revised 14 January 2018; Accepted 21 January 2018; Published 26 February 2018

Academic Editor: Roberto Tonelli

Copyright (C) 2018 Yujing Yang and Wenzhe Tang. This is an open access article distributed under the Creative Commons Attribution License, which permits unrestricted use, distribution, and reproduction in any medium, provided the original work is properly cited.

This paper establishes a model on the upstream and downstream relationship among private enterprises, provincial and local officials, and the central government in the real estate market using the population ecology theory of mutual relations among individual species from the perspective of business ecosystem. A dynamic model is introduced and the complex dynamical behaviors of such a predator-prey model are investigated by means of numerical simulation. The local stability conditions and complex dynamics are investigated, and the existence of chaos is discussed in the sense of Marotto theorem; bifurcation diagrams, Lyapunov exponents, sensitivity analysis for initial values, and time history figure of the system are mapped out and discussed. This shows that there are two routes to complicated dynamics, one of which is the cascade of flip bifurcations resulting in periodic cycles (and chaos), and the other one is Neimark-Sacker bifurcation which produces attractive invariant closed curves. We arrive at conclusions that the phenomenon of chaos is harmful to private enterprises, and unstable behavior is often unfavorable. Thus, linear feedback control is applied to drive the model to a stable state when the system exhibits chaotic behaviors, achieving the goal of eliminating the negative effects to a large extent.

\section{Introduction}

In 2017, the real estate policy adheres to the keynote that "the house is used for living, not for speculation" and that the local area is dominated by urban agglomerations. The monthly average transaction area of 50 representative urban commercial residential markets was 29.43 million square meters, down $24.2 \%$ from the same period last year, with an absolute value lower than the same period in 2015, from January to November 2017 according to preliminary statistics. According to different levels of cities, the number of firsttier representative cities has fallen most obviously, and the absolute level is the same as that of 2011. Sales in second-tier cities fell to the level of 2015. Turnover of third-tier cities is lower than that of 2016 but has relatively high absolute scale. In the Beijing-Tianjin-Hebei region, the Yangtze river delta, the pearl river delta, the middle reaches of the Yangtze river, and the five urban Chengdu-Chongqing agglomerations, large-sized private enterprises occupy more than $60 \%$ of the total area and they focus on the major urban agglomeration market from the perspective of distribution.

In 2017, the concentration of the real estate industry will continue to improve, and new changes will take place in the development pattern of enterprises. As for the private enterprises, they will continue to grasp the incremental market space, expand the key city circle and urban agglomeration deeply, focusing on different urban development processes, and improving the competitiveness.

Chaos has become a hot topic in the competition of economics. Puu [1] studied different strategies which are the Cournot model, the Stackelberg case, and the dynamic system of a duopoly game and investigated stable equilibrium point, cycles, bifurcation, and chaos of the systems. Based on the analysis, several useful issues are investigated either analytically or numerically.

Agiza et al. [2-4] have investigated the dynamics of a nonlinear discrete-time duopoly game and showed how the dynamics of the game depend on the model parameters. 
Numerical simulations are presented to show that players with heterogeneous beliefs make the duopoly game behave chaotically, obtaining some valuable conclusions. Ma et al. [57] have researched the chaotic theory and complex dynamics in several fields and resolved many economic issues. Yu and Liao [8] have studied new estimations for the globally attractive and positive invariant set of the family of the Lorenz systems, and got some conclusions. Wang et al. [9] have introduced a new simple system with a butterfly chaotic attractor which has rich and complex dynamics. It has drawn much more attention to scholars in the fields of chaos because there are important theoretical and practical meanings and wide foreground to further pursue this research. Elsadany $[10,11]$ has studied a dynamic Cournot game characterized by three boundedly rational players by three nonlinear difference equations and analyzed the stability of the system. The global complexity analysis is helpful for behavior taking some effective measures, avoiding the collapse of the output dynamic competition game, and obtaining some practical and theoretical significance in the practice. Ahmed and Agiza [12] have discussed a dynamical system of $n$ competitors in a Cournot game and pointed out the effect of a modification of the price-demand relation. In particular, cooperation and multiteam games in a food chain model had become popular in the fields of chaos in recent years. Zhao and Lv [13] have researched a three-species food chain model with a Beddington-DeAngelis functional response and got some useful conclusions. Elettreby and Hassan [14] have proposed two different versions of the multiteam model where a team of two firms compete with another team. Elettreby and Mansour [15] have studied an incomplete information dynamical system, analyzed the equilibrium solutions and the conditions of their local asymptotic stability for the static and the dynamic monopoly, and formulated and studied the multiteam dynamic Cournot game. Ahmed et al. [16] have concentrated on the fractional-order predator-prey model and the fractional-order rabies model and studied the stability of equilibrium points. Elettreby [17] has proposed a new multiteam prey-predator model, in which the prey teams help each other. They observed that there is no help between the prey teams when predator is absent. Therefore, they researched the global stability and persistence of the model with no help and obtained some meaningful results. Upadhyay et al. [18] have studied the effects of top predator interference on the dynamics of a food chain model involving an intermediate and a top predator and observed that there are different types of attracting sets including chaos. Furthermore, increasing the top predator interference stabilizes the system, while increasing the normalization of the residual reduction in the top predator population destabilizes the system, drawing some useful conclusions. Elettreby and ElMetwally [19] have applied multiteam concept to the preypredator model and investigated the global stability and persistence of the model without help. Liu et al. [20] have discussed appointed-time consensus (accurate and practical designs) and obtained some meaningful conclusions. Wen et al. [21] have researched containment of higher-order multileader multiagent systems and got some valuable results.
Cotter and Roll [22] have researched a comparative anatomy of residential REITs and private real estate markets: returns, risks, and distributional characteristics. Thus, it is worth analyzing and extending it in this area further. Zhao et al. [23-25] have introduced the motion-planning approaches to solve the distributed consensus problems and studied the distributed optimization problem for continuoustime multiagent systems with general linear dynamics and finite-time tracking problem of a multiagent system with second-order nonlinear dynamics by providing a numerical example to illustrate the effectiveness of the analytical results, obtaining some valuable conclusions.

The topic of this study is within the field of complexity, and relevant papers have been reviewed, such as $[1-7,9-$ 11]. Specifically, the evolution of the real estate market is very complex and changeable, similar to the biological evolutionary process, falling within the scope of complexity. Motivated by this, the study uses biological evolutionary process to explain the economic phenomenon in real estate market. However, little research has quantitatively analyzed this process in real estate market from the biological view. The model in this research is constructed to demonstrate the economic process in real estate market from the perspective of the biological evolution, which is closely related to the literature $[13,16,19]$.

The relationships among private enterprises, provincial and local officials, and center government are just similar to the relationship in the food chain. Thus, we propose the 3D continuous predator-prey model to analyze the evolution in the real estate market. Three innovations can be obtained in this paper: (1) unlike the discrete model researched in the past, we use 3D continuous dynamic model to analyze the evolution in real estate market. (2) It is a new perspective to introduce the predator-prey model to analyze the evolution among private enterprises, provincial and local officials, and center government in real estate market. (3) Flip bifurcations with loss of equilibrium stability result in a stable cycle of period two, and the Neimark-Sacker bifurcations for private enterprises and provincial and local officials with orbits spiralling away from a stable invariant closed curve describing quasi-periodic motions towards the equilibrium are analyzed in this paper.

This paper is designed as follows: in Section 2, an ecological equation is proposed. In Section 3, the equilibrium point and stability of the dynamic equation are discussed in the sense of Marotto theorem. In Section 4, dynamical characteristics of the system are analyzed; numerical simulations are used to demonstrate complex dynamics of the system. Flip and Neimark-Sacker bifurcation diagrams and attractors are drawn and analyzed by Lyapunov index and Lyapunov dimension. Sensitivity analysis for initial values is studied and time history figure of system is mapped out. In Section 5, linear feedback control is designed for driving the chaotic system to a steady state, achieving the purpose of chaos control. Finally, the finding and future researches directed are presented in the section of the conclusions. 


\section{Construction of Dynamic Model}

2.1. Model Construction. There are relationships similar to the ecological food chain relationships between species in the real estate market. Simulate ecology features, and introduce ecological equations.

$$
\begin{aligned}
& \frac{d X}{d T}=a_{1} X\left(1-\frac{X}{K}\right)-\frac{\omega * X Y}{X+D} \\
& \frac{d Y}{d T}=-a_{2} Y+\frac{\omega_{1} X Y}{X+D_{1}}-\frac{\omega_{2} Y Z}{Y+D_{2}+b Z} \\
& \frac{d Z}{d T}=c z-\frac{\omega_{3} Z^{2}}{Y} \\
& \frac{d Z}{d T}=c z^{2}-\frac{\omega_{3} Z^{2}}{Y+D_{3}}
\end{aligned}
$$

In this model, all the parameters are considered to be positive constants. $X$ represents the number of firms that are privately owned in real estate market. Real estate market is similar to the characteristics of the ecology. In ecology, the competition is the original power of progress of a population. From the point of the real estate market of industrial cluster, numerous real estate enterprises gather together, and each real estate enterprise provides similar services or production to the real estate; thus, there is competition between them. According to a 2015 real estate enterprise sales ranking, the private enterprises were divided into three levels: first class: sales $\geq 100$ billion; there are six companies, Vanke Co., Ltd., Shanghai Greenland (group) Co., Ltd., Poly Real Estate (Group) Co., Ltd., China's Overseas Development Co., Ltd., Evergrande Real Estate Group Co., Ltd., and Country Garden Holdings Co., Ltd.; the second class: 20 billion $\leq$ sales < 100 billion; the third class: sales $<20$ billion. The first-class private enterprises have the characteristics of occupying more market shares and large amounts of funds, with strong competitiveness and medium-sized fund share, general development of cooperation, and self-sufficiency capacity. The second-class private enterprises have the characteristics of market shares in general: medium-sized fund share, general development of cooperation, and self-sufficiency capacity. The third class private enterprises have low market share, small capital shares, and small-scale characteristics. The development is much more difficult, requiring foreign aid to maintain survival. The first kind of private enterprises has great strength, can assist the third type of enterprises, or join cooperation evolution and development with the second category of private enterprises. Private enterprises in the second category compete or cooperate with other companies, having their own characteristics. The third class private enterprises have relatively weak strength, requiring help of other companies, especially in assisting the first-class private enterprises, in order to maintain survival in real estate market.

$Y$ is the number of provincial and local officials who become predators.

$Z$ is the center government, which can be growthoriented central leaders who are intelligent designers of institutions that moderate the predator-prey relationship. The ecosystem on the top of the predator-prey interactions is the institutional framework subject to adjustment by the central government.

$X Y, Y Z$ is the interaction term, which indicates the encounter rate of random prey with a random predator.

$a_{1}$ is the intrinsic rate of the prey population $X$; it means that the number of private enterprises grows at a natural rate $a_{1}$, which depends on their intrinsic growth rate and how private properties are protected. This means that if there were better protection, it will be a higher $a_{1}$.

$a_{2}$ is the predator mortality rate. It is the intrinsic death rate of the intermediate predator $Y$ in the absence of the only food $X$; a lower rate indicates a lower predator mortality rate.

$c$ measures the rate of self-reproduction of top predator $Z$; in this paper it is central government.

$K$ represents the carrying capacity. $\omega_{3}$ represents the residual loss in $Z$ population due to severe scarcity of its favorite food $Y$.

$D_{2}$ is the value of which per capita removal rate of $Y$ becomes $\omega_{2} / 2$.

$D$ and $D_{1}$ quantify the extent that external environment provides protection to the private enterprises in real estate market and can be considered as a measure of the effectiveness for the prey in evading the attack of predator.

$\omega, \omega_{1}, \omega_{2}, \omega_{3}$ are the maximum values which per capita growth rate can attain.

$c Z^{2}$ signifies the fact that mating frequency is directly proportional to the number of males as well as that of females present at any instant of time $t . D_{3}$ normalizes the residual reduction of $Z$ because there is severe scarcity of the favorite food. Thus, it can be acceptable biologically that top predator $Z$ goes extinct and goes unboundedly due to the absence of intermediate predator in the real estate market. If market economy brings about more private enterprises satisfying the availability of market resources increases, the system will be drawn from a stable state to overexploitation by provincial and local officials.

We use the following nondimensionalized variables and parameters to simplify the model:

$$
\begin{aligned}
& t=a_{1} T, \\
& x=\frac{X}{K}, \\
& y=\frac{\omega Y}{a_{1} K}, \\
& z=\frac{\omega \omega_{2} Z}{a_{1}^{2} K}, \\
& a=\frac{D}{K}, \\
& b=\frac{a_{2}}{a_{1}}, \\
& c=\frac{\omega_{1}}{a_{1}},
\end{aligned}
$$




$$
\begin{aligned}
& d=\frac{D_{1}}{k}, \\
& e=\frac{a_{1} b}{\omega_{2}}, \\
& f=\frac{\omega D_{2}}{a_{1} K}, \\
& g=\frac{a_{1} c K}{\omega \omega_{2}}, \\
& h=\frac{\omega_{3}}{\omega_{2}}, \\
& k=\frac{\omega D_{3}}{a_{1} K} .
\end{aligned}
$$

Thus, we obtain

$$
\begin{aligned}
& \dot{x}=x(1-x)-\frac{x y}{x+a} \\
& \dot{y}=-b y+\frac{c x y}{x+d}-\frac{y z}{y+e z+f} \\
& \dot{z}=g z^{2}-\frac{h z^{2}}{y+k} .
\end{aligned}
$$

According to the regional characteristics, in particular, there are many differences in the development process between the first-tier cities and backward area. The first-tier cities have rapid economic development and easily accept new knowledge. In order to study the dynamic system, we can analyze it from discrete and continuous systems, respectively. In this paper, we analyze it from discrete system. Parameters $\sigma_{1}, \sigma_{2}$, and $\sigma_{3}$ are adjustment speed for private enterprises, provincial and local officials, and central government. When $\sigma_{1}$ is large, it shows the development speed in backward area, and $X$ marked the private enterprises in the backward area. When $\sigma_{1}$ is small, it shows the development speed in first-tier cities; accordingly, $X$ shows the private enterprises in first-tier cities.

$$
\begin{aligned}
& x(n+1)=x(n)+\left[x(n)(1-x(n))-\frac{x(n) y(n)}{x(n)+a}\right] \sigma_{1} \\
& y(n+1) \\
& =y(n) \\
& +\left[-b y(n)+\frac{c x(n) y(n)}{x(n)+d}-\frac{y(n) z(n)}{y(n)+e z+f}\right] \sigma_{2} \\
& z(n+1)=z(n)+\left[g z(n)^{2}-\frac{h z(n)^{2}}{y(n)+k}\right] \sigma_{3} \text {. }
\end{aligned}
$$

\section{Stable Analysis}

By the dynamics equation

$$
\begin{aligned}
& f_{1}(x, y, z)=1-x-\frac{y}{x+a}=0 \\
& f_{2}(x, y, z)=-b+\frac{c x}{x+d}-\frac{z}{y+e z+f} \\
& f_{3}(x, y, z)=g z-\frac{h z}{y+k}
\end{aligned}
$$

we obtain the equilibrium points: $p=\left(x^{*}, y^{*}, z^{*}\right), x^{*}=$ $(1 / 2)\left[(1-a)+\sqrt{(1-a)^{2}-4 M_{1}}\right], M_{1}=(h-g(a+k)) / g$,

$$
\begin{aligned}
y^{*} & =\frac{h-g k}{g} \\
z^{*} & =\frac{\left(y^{*}+f\right) M_{2}}{1-e M_{2}} \\
M_{2} & =-b+\frac{c x^{*}}{x^{*}+d} .
\end{aligned}
$$

The Jacobian matrix can be written as

$$
J=\left(\begin{array}{ccc}
\frac{y}{(a+x)^{2}-1} & -\frac{1}{a+x} & 0 \\
\frac{c}{d+x}-\frac{c x}{(d+x)^{2}} & \frac{z}{(f+y+e z)^{2}} & \frac{e z}{(f+y+e z)^{2}}-\frac{1}{f+y+e z} \\
0 & \frac{h z}{(k+y)^{2}} & g-\frac{h}{k+y}
\end{array}\right)
$$

and the characteristic polynomial is

$$
\begin{aligned}
& p(\lambda)=\lambda^{3}+m_{1} \lambda^{2}+m_{2} \lambda+m_{3} \\
& H(1)=\left(m_{1}\right) \\
& H(2)=\left(\begin{array}{cc}
m_{1} & 1 \\
m_{3} & m_{2}
\end{array}\right)
\end{aligned}
$$

$$
H(3)=\left(\begin{array}{ccc}
m_{1} & 1 & 0 \\
m_{3} & m_{2} & m_{1} \\
0 & 0 & m_{3}
\end{array}\right) \text {; }
$$

for (9)-(11), they must satisfy $\operatorname{det} H_{j}>0(j=1,2,3)$, and then we get

$$
\operatorname{det} H_{1}=m_{1}>0
$$




$$
\begin{aligned}
& \operatorname{det} H_{2}=m_{1} m_{2}-m_{3}>0 \\
& \operatorname{det} H_{3}=m_{3}\left(m_{1} m_{2}-m_{3}\right)>0 .
\end{aligned}
$$

According to Routh-Hurwitz criteria, we can obtain the conditions for the local stability of equilibrium:

$$
\begin{aligned}
& m_{1}>0 \\
& m_{1} m_{2}-m_{3}>0 \\
& m_{3}>0
\end{aligned}
$$

The stability of the system is guaranteed under condition (13). By numerical simulation, when $a=0.44, b=1.14, c=$ 2.93, $d=0.54, e=0.21, f=0.1, g=0.35, h=0.2, k=$ $0.25, x=0.1, y=0.1, z=0.1$, we get the eigenvalues of the equilibrium point $p^{*}=\left(x^{*}, y^{*}, z^{*}\right)$ as follows: $\lambda_{1}=-0.3909$, $\lambda_{2}=0.3814+0.6538 i$, and $\lambda_{3}=0.3814-0.6538 i$, and $\lambda_{1}$ is negative real number, while $\lambda_{2}$ and $\lambda_{3}$ are a pair of real positive virtual roots. It can be calculated that $m_{1}=-2.05$, $m_{2}=2.02$, and $m_{3}=-0.12$; therefore, equilibrium point is unstable.

$$
\operatorname{Df}\left(p^{*}\right)=\left(\begin{array}{ccc}
\frac{y}{(a+x)^{2}-1} & -\frac{1}{a+x} & 0 \\
\frac{c}{d+x}-\frac{c x}{(d+x)^{2}} & \frac{z}{(f+y+e z)^{2}} & \frac{e z}{(f+y+e z)^{2}}-\frac{1}{f+y+e z} \\
0 & \frac{h z}{(k+y)^{2}} & g-\frac{h}{k+y}
\end{array}\right) .
$$

Proof. Denote $A=\operatorname{Df}\left(p^{*}\right)$, since $A$ has distinct eigenvalues $\lambda_{1}, \lambda_{2}, \lambda_{3}$ exceeding the unity in absolute value, and an orthonormal matrix $T$ exists, such that

$$
A=T^{-1}\left(\begin{array}{ccc}
\lambda_{1} & 0 & 0 \\
0 & \lambda_{2} & 0 \\
0 & 0 & \lambda_{3}
\end{array}\right) T:=T^{-1} \wedge T
$$

It follows that $\|A p\|=\left\|T^{-1} \wedge T p\right\|=\|\wedge T p\| \geq \lambda_{\text {min }}\|T p\|=$ $\lambda_{\text {min }}\|p\|$, where $\lambda_{\text {min }}=\min \left\{\left|\lambda_{1}\right|,\left|\lambda_{2}\right|,\left|\lambda_{3}\right|\right\}$. There is a real constant according to the intermediate value theorem in calculus, $0<\theta<1$, such that $\|f(p)-f(q)\|=\|[A+o(q+\theta(p-$ $\left.\left.q)-p^{*}\right)\right](p-q)\|\geq \lambda\| p-q\left\|-o\left(\left\|q+\theta(p-q)-p^{*}\right\|\right)\right\| p-q \|$. It is not difficult to verify that there exists a real constant, $r>0$, small enough, such that $\|f(p)-f(q)\|>s\|p-q\|$, where $s>1$, for all $p, q \in B\left(p^{*} ; r\right)$. And there exists a point $\bar{p} \in B\left(p^{*} ; r\right)$, with $\bar{p} \neq p^{*}$, such that, for some positive integer $n, f^{n}(\bar{p})=p^{*}$ and $f^{m}(\cdot)$ is differentiable at $\bar{p}$ with $f^{m}(\bar{p}) \neq 0$ according to differential chain rule. Consequently, $f$ is expanding in the neighborhood of the fixed point $p^{*}$, and the fixed point $p^{*}$ is said to be a snapback repeller. According to Marotto theorem $[26,27]$, the existence of chaos in the system can be proved.

The equilibrium point becomes unstable in certain conditions and varies with adjustment parameters in real estate market. In particular, a flip bifurcation occurs and NeimarkSacker bifurcation takes place and varies with parameters in the dynamic system in real estate market. It will become more and more unstable and difficult to control with the increasing of adjustment parameters, which indicates that the faster the development is for the private enterprises, the more fluctuating the evolution becomes.

Stability means that the state is fixed in the real estate market and that every behavior can get fixed benefit in every time period; thus, stability is beneficial for private enterprisers in the real estate market to make long-time strategies.
For provincial and local officials and the central government, it will be easy to make some principles or regulations in the real estate market. Chaos means that the real estate market is irregular and vibratile; it is difficult for behaviors to make long-term strategies. Therefore, from the perspective of strategy making and adjustment, stability is much better and chaos is much worse. The appearance of chaos in the economic system is harmful to private enterprises, provincial and local officials, and central government. Thus, in order to avert the risk, it is expedient for the behaviors to maintain at a stable state.

\section{The Complexity Analysis of the Model}

4.1. Lyapunov Index and Lyapunov Dimension. Numerical efforts are devoted to the analysis of the abundant complex dynamics. When $a=0.44, b=1.14, c=2.93, d=0.54$, $e=0.21, f=0.1, g=0.35, h=0.2, k=0.25$, $x=0.1, y=0.1$, and $z=0.1$, we obtain three values of the Lyapunov exponents by Wolf algorithm: $L_{1}=0.003101$, $L_{2}=0.001157$, and $L_{3}=-0.007128$. With the variation of parameters, the system generates a wealth of complex and diverse hyperchaotic dynamical behaviors. The maximum Lyapunov exponent is positive, which means that the system has chaotic characteristics. $L_{1}$ and $L_{2}$ are positive, and the third Lyapunov exponent is negative; therefore, the dynamical system is hyperchaotic. Kaplan-Yorke dimension is a typical characteristic of chaos and hyperchaos characteristics, which can be expressed as

$$
D_{k y}=k+\sum_{i=1}^{k} \frac{L_{i}}{\left|L_{k+1}\right|} \text {, }
$$

where $k$ is a maximum of $i$ which simultaneously satisfies the conditions $\sum_{i=1}^{k} \geq 0$ and $\sum_{i=1}^{k}<0$ and $L_{i}$ is arranged 


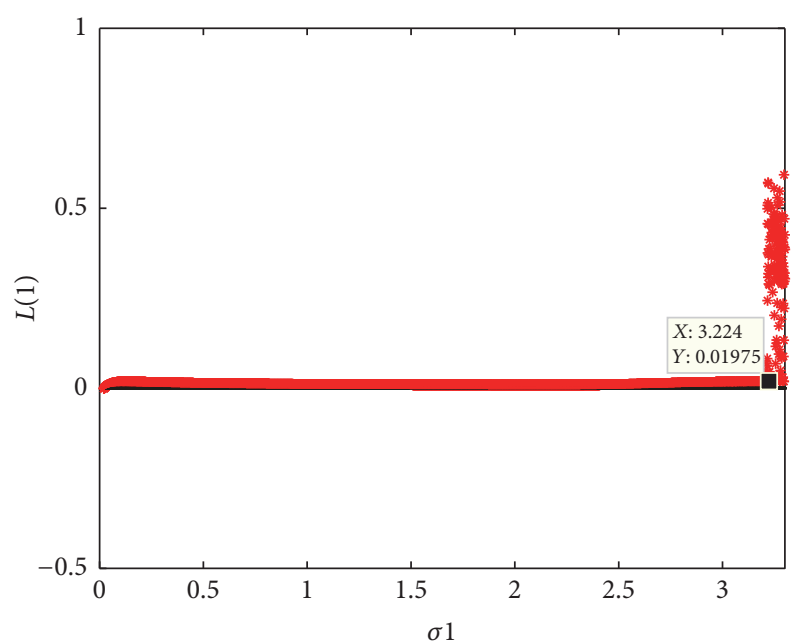

(a) The first Lyapunov index when $a=0.44, b=1.14, c=2.93, d=$ $0.54, e=0.21, f=0.1, g=0.35, h=0.2, k=0.25$

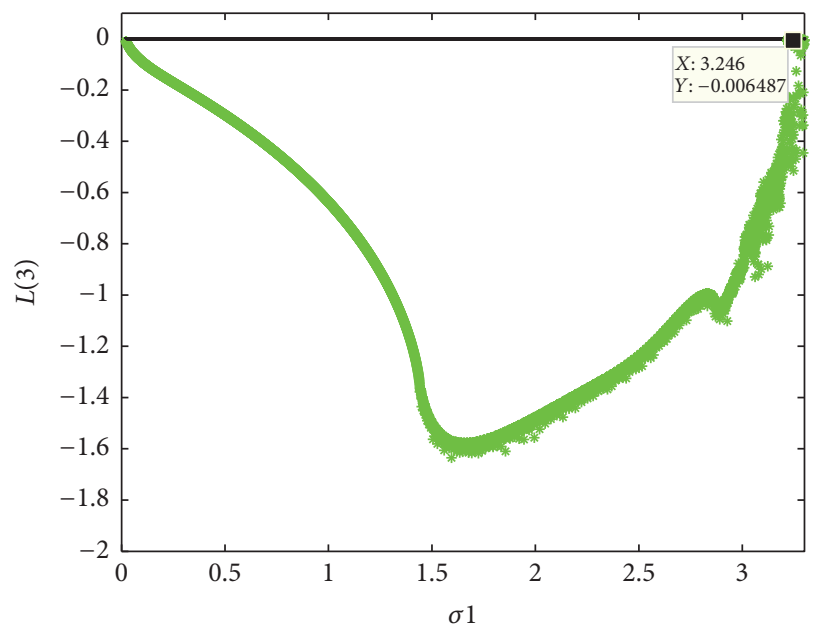

(c) The third Lyapunov index when $a=0.44, b=1.14, c=2.93, d=$ $0.54, e=0.21, f=0.1, g=0.35, h=0.2, k=0.25$

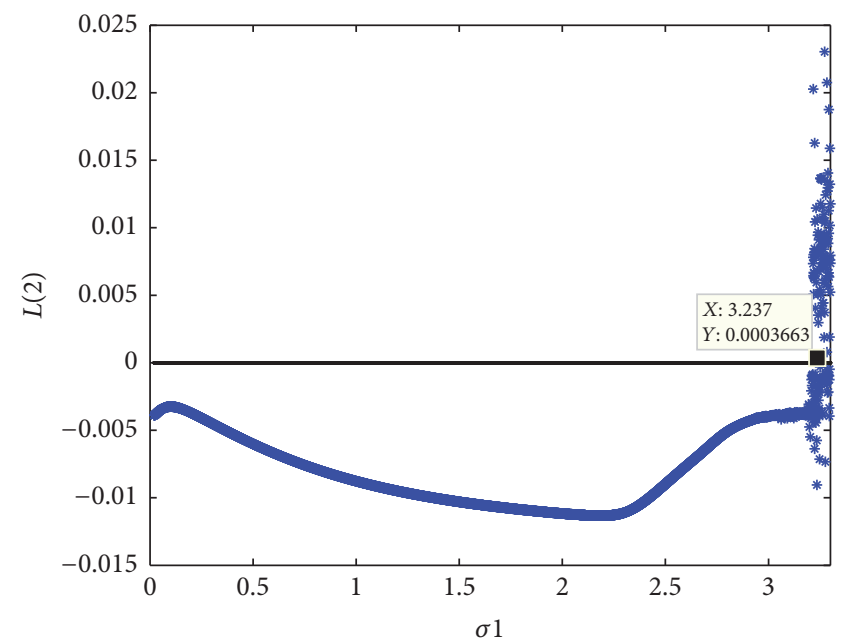

(b) The second Lyapunov index when $a=0.44, b=1.14, c=2.93, d=$ $0.54, e=0.21, f=0.1, g=0.35, h=0.2, k=0.25$

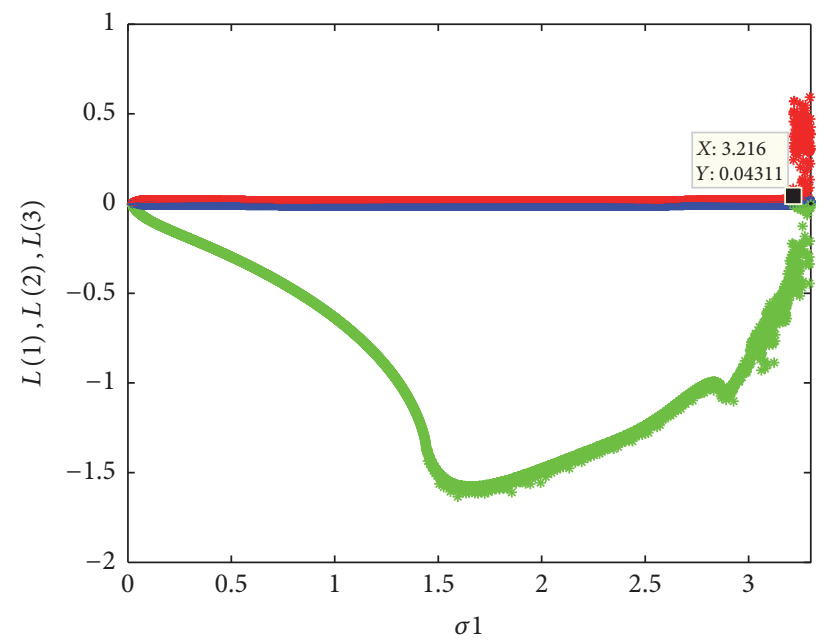

(d) Lyapunov index when $a=0.44, b=1.14, c=2.93, d=0.54, e=$ $0.21, f=0.1, g=0.35, h=0.2, k=0.25$

Figure 1: Lyapunov index of dynamic system in real estate market when $a=0.44, b=1.14, c=2.93, d=0.54, e=0.21, f=0.1, g=$ $0.35, h=0.2, k=0.25$.

in a descending order. $D_{k y}$ is the largest border of fractal dimension. From the analysis above, the value of $k$ is fixed as 2 . Therefore, the Kaplan-Yorke dimension can be written as

$$
D_{k y}=2+\frac{0.003101+0.001157}{|-0.007128|}=2.597363 .
$$

From $D_{k y}$, it is can be seen that the system has nonlinear complex dynamical behaviors. It is also said that at this time the dynamic economic system is a hyperchaotic system with fractal structure. The evolution of system becomes unpredictable. The private enterprisers or related industries will adjust their strategy in response to violent and frequent irregular market fluctuation. At the same time single real estate company's business is conducted to other companies through various forms of behaviors due to the interaction of the market in the first-class real estate companies and other counterparts. Other industry stakeholders adjust strategy and rush into the unhealthy competitive environment.

Figure 1 is the Lyapunov exponent of the dynamic system, which indicates the appearance of chaos. From Figures 1(a), $1(\mathrm{~b})$, and $1(\mathrm{c})$, we can see when $\sigma_{1}<3.2$, and all the Lyapunov exponents are negative, which means that the system is in a stable state at this time. At $\sigma_{1}=3.2$, all the Lyapunov exponents are zero. when $\sigma_{1}>3.2$, the Lyapunov exponents become positive. Thus, the system rushes into a chaotic state, and all the behaviors of private enterprises, provincial and local officials, and central government are difficult to make strategies. We put the three Lyapunov exponents in the same figure and obtain Figure 1(d).

4.2. Bifurcation Diagrams and Attractors. We continue to consider the influence of the adjustment parameters $\sigma_{1}$ and $\sigma_{2}$ on the system by performing several simulations to verify the 


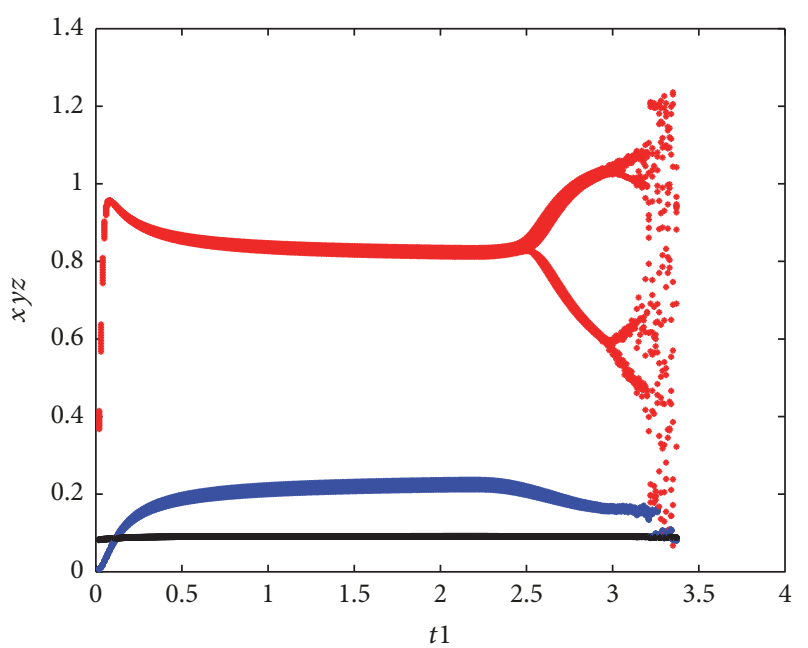

FIGURE 2: Flip bifurcation diagram for private enterprises, provincial and local officials, and central government, respectively, when $a=$ $0.44, b=1.14, c=2.93, d=0.54, e=0.21, f=0.1, g=$ $0.35, h=0.2, k=0.25$.

results of (13) and to describe the different qualitative complex behaviors, particularly, when the equilibrium becomes unstable. Figure 2 portrays the characteristic behavior of flip bifurcations for private enterprises, provincial and local officials, and central government, respectively. When $\sigma_{1}$ is used as a bifurcation parameter, as shown in Figure 2, the equilibrium point $\left(x^{*}=0.725, y^{*}=0.321\right.$, and $z^{*}=$ 0.256 ) is locally stable for small values of parameters $\sigma_{1}$. With the increase of $\sigma_{1}$, the equilibrium point becomes unstable and the strategies of private enterprises, provincial and local officials, and central government are bifurcating from the equilibrium to the first period orbit when $\sigma_{1}=2.52$.

Figure 2 is the flip bifurcation diagram with variation of parameter $\sigma_{1}$. When $a=0.44, b=1.14, c=2.93$, $d=0.54, e=0.21, f=0.1, g=0.35, h=0.2, k=0.25$, $x=0.1, y=0.1, z=0.1, \sigma_{2}$ and $\sigma_{3}$ are fixed. From Figure 2, when $\sigma_{2}=0.03, \sigma_{3}=0.06$, equilibrium point is $\left(x^{*}=0.725\right.$, $y^{*}=0.321, z^{*}=0.256$ ). From bifurcation diagram, when $\sigma_{1} \in[0,2.52]$, the system is stable; when $\sigma_{1}>2.52$, system starts to produce bifurcation behaviors; $\sigma_{1}>3.2$, a cascade of flip bifurcations results in chaos. Similarly, Figure 3 is the flip bifurcation diagram with variation of $\sigma_{2}$ for provincial and local officials. Bifurcation diagram with variation of $\sigma_{3}$ is not discussed in this paper.

Figure 4 shows bifurcation diagrams of dynamic system in real estate market and proves the existence of a Neimark-Sacker bifurcation according to (13). Figure 4(a) said Neimark-Sacker bifurcation diagram with variation of parameter $a$ for private enterprises, and "parameter $a$ " can be considered the effectiveness of a measure for private enterprises in evading the regulation effect of provincial and local officials and central government in the real estate market. From the portray in Figure 4(a), it is helpful for behaviors to make valuable measures in real estate market. Figure 4(b) shows that Neimark-Sacker bifurcation diagram of provincial and local officials varies with parameter $b$. Take

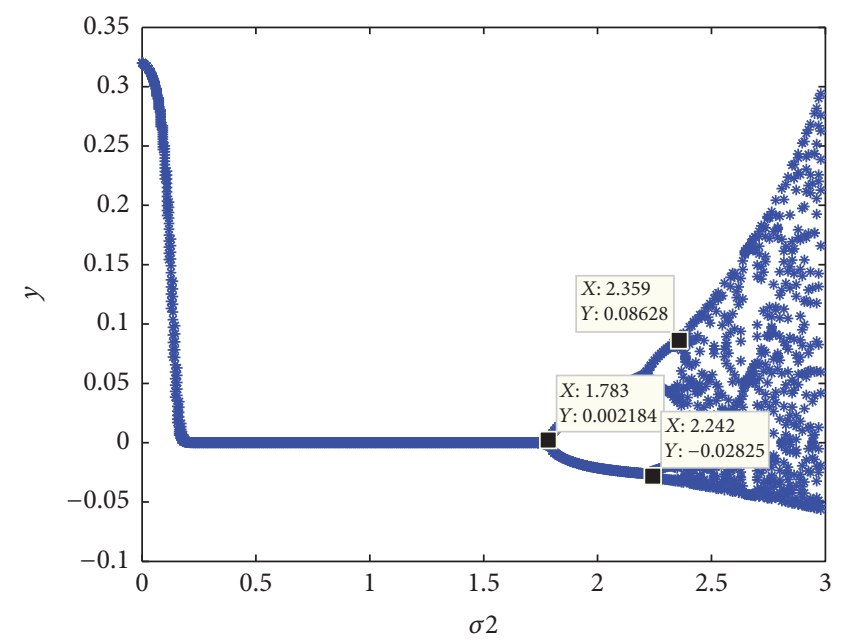

FIGURE 3: Flip bifurcation diagram of provincial and local officials in the dynamic system when $a=0.44, b=1.14, c=2.93, d=$ $0.54, e=0.21, f=0.1, g=0.35, h=0.2, k=0.25$.

the leasing market in real estate market as an example; at present the floating population is mainly concentrated in the first-tier cities in the urban agglomeration, which is the main position for the development of the leasing market in the future. The largest number of the floating population is in ten Chinese cities-Shanghai, Beijing, Shenzhen, Dongguan, Tianjin, Chengdu, Wuhan, Chongqing, Guangzhou, and Foshan-according to the sixth census data in 2010. Thanks to the support and encouragement of the policy, the leasing market will get well developed in the megacities and surrounding urban agglomerations several years from now. The government can take effective measures to regulate and guide the private enterprises according to Figure 4(b). Figure 5 shows phase portraits according to flip bifurcation diagram with different parameters in Figure 2 in the dynamic system in the real estate market, which is another characteristic of the system. Figure 6 shows chaos attractors of dynamical system when $a=0.44, b=1.14, c=2.93, d=0.54, e=0.21$, $f=0.1, g=0.35, h=0.2$, and $k=0.25$, and corresponding eigenvalues are $0.001811,-0.083406$, and -0.591990 .

Fractal dimension is

$$
D_{k y}=2+\frac{0.001811}{0.083406}=2.02 .
$$

4.3. Sensitivity Analysis for Initial Values. As can be seen from Figure 7, when $a=0.44, b=1.14, c=2.93, d=0.54, e=0.21$, $f=0.1, g=0.35, h=0.2$, and $k=0.25, \sigma_{1}=3.2, \sigma_{2}=$ 0.03 , and $\sigma_{3}=0.06$, and initial values are $0.1,0.1,0.1$, when the gain of central government changes to 0.1001 , the private enterprises performance sensitivity to the initial value.

Figure 8 indicates sensitivity analysis to the initial value of the provincial and local officials who become predators; Figure 9 indicates the sensitivity analysis to the initial value of the central government; thus, we obtain some valuable conclusions: there are abundant dynamic behaviors in the evolution in real estate market. Under the chaotic state 


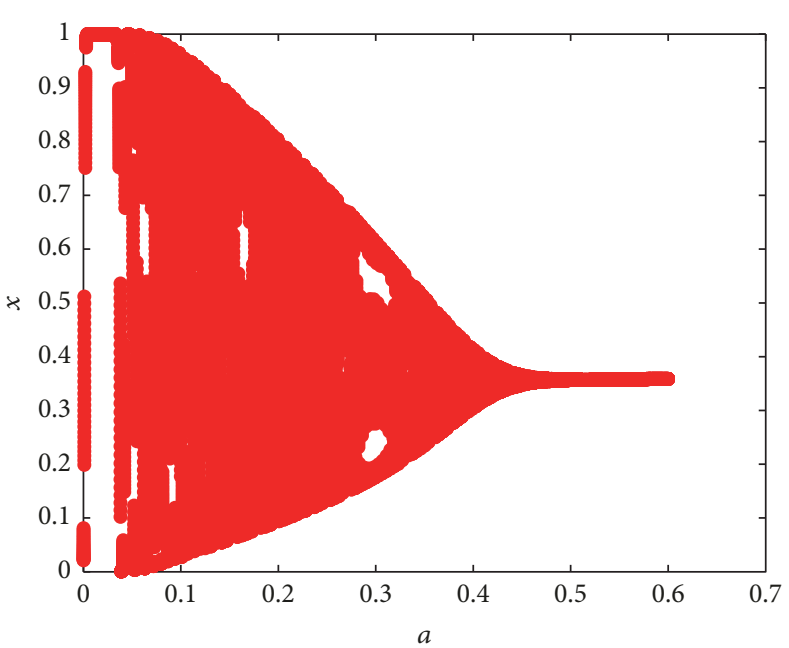

(a) Neimark-Sacker bifurcation of private enterprises with variations of parameter $a$

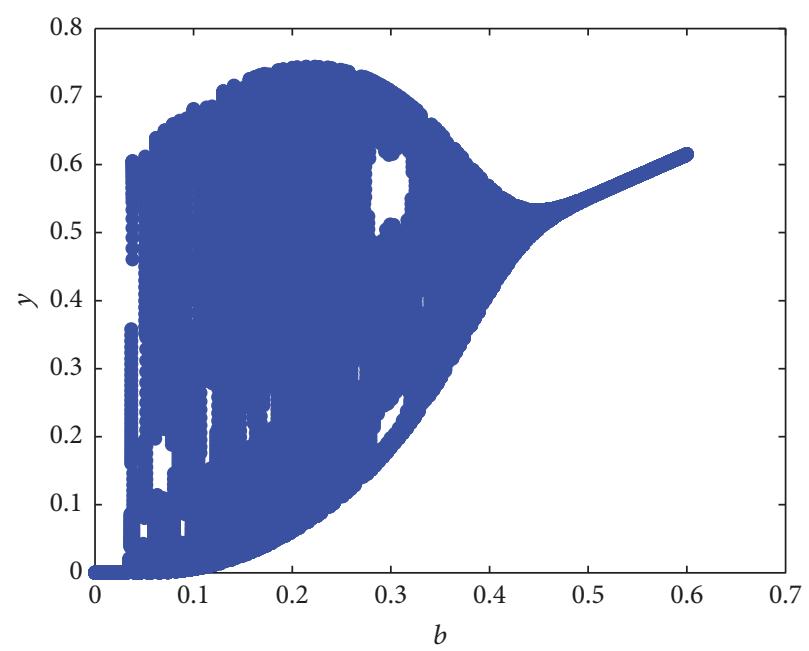

(b) Neimark-Sacker bifurcation of provincial and local officials with variations of parameter $b$

FIGURE 4: Neimark-Sacker bifurcations in the dynamic system in real estate market.

conditions, slight changes for the central government will have an impact on the entire system. It can also be seen from Figure 7 that the variations will have a greater effect on the private enterprises in the real estate market. The private enterprises will have more intense and greater fluctuations compared with provincial and local officials and central government. The slight variations for the central government not only make them produce butterfly effect but also have big impact on private enterprises and the provincial and local officials. Thus, private enterprises should increase coordination and cooperation to increase the ability to protect and not be concerned about their own development but take into account the development of related businesses in order to promote the healthy development of the real estate market. Figures 10, 11, and 12 indicate the sensitivity analysis of the system when $a=0.44, b=1.14, c=2.93, d=0.54$, $e=0.21, f=0.1, g=0.35, h=0.2$, and $k=0.25$ and initial value varies from $0.1,0.1,0.1$ to 0.1001 . When the system is in a chaotic state, all the behaviors will have sensitivity of dependence because of the slight variation of 0.0001 of the private enterprises in the real estate market. As can be seen from Figure 8, it will have a much higher effect on the private enterprises, because private enterprises $X$ are considered food of the provincial and local officials $Y$ and central government $Z$ and lack measures of selfprotection in the real estate market. Accordingly, influence on the provincial and local officials $Y$ and central government $Z$ is weak, and the curve only shows offset.

4.4. Time History Figure of System. Figure 13 explains time history figure of the dynamic system in the real estate market when $a=0.44, b=1.14, c=2.93, d=0.54, e=0.21, f=0.1$, $g=0.35, h=0.2, k=0.25$, and initial values are $0.1,0.1,0.1$, in which red line marked the time history figure of the private enterprises in the real estate market; pink line marked the time history figure of the provincial and local officials; green line marked the time history figure of the central government.

\section{The Model with Linear Feedback Control}

There is a steady state in the complex process of competition and cooperation in the real estate market. It is similar to the ecological evolution process. There are variable factors (such as government policy and the advent of the financial crisis) making the temporary stable condition broken; thus, the system rushes into a chaotic state. All of the private enterprises in the real estate market will be unpredictable. In reality, there are all kinds of competition in the process of evolution. Thus, the private enterprises should take measures to resist risks, such as cooperating with the other private enterprises, building a competitive team, or taking the merger and assimilation of other private enterprises to enhance their strength. Chaotic behavior will be detrimental to the entire real estate market and puts a huge negative impact on the whole process of economic operation in our country. Therefore, taking corresponding measures to control the chaos will be needed.

Thus, we put controller $K$ in the dynamic system and obtain a new model (9):

$$
\begin{aligned}
& x(t+1)=f(x(t), y(t), z(t)) \\
& y(t+1)=g(x(t), y(t), z(t)) \\
& z(t+1)=g(x(t), y(t), z(t))-K z(t)
\end{aligned}
$$

substituting it into the original equation, the model can be written as

$$
x(t+1)=x(t)+\left[x(t)(1-x(t))-\frac{x(t) y(t)}{x(t)+a}\right] \sigma_{1}
$$




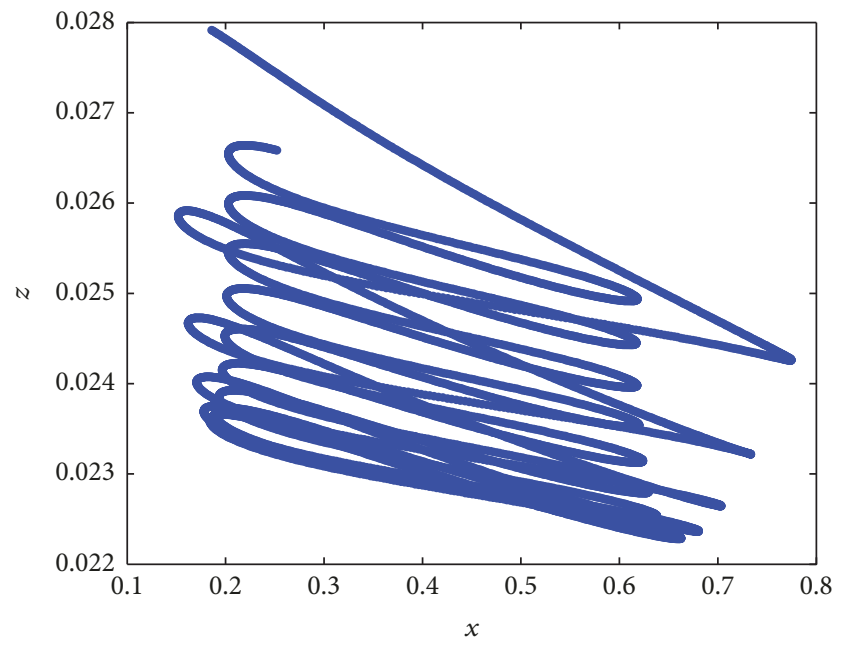

(a) Projection onto the $x-z$ plane when $t_{1}=0.01$

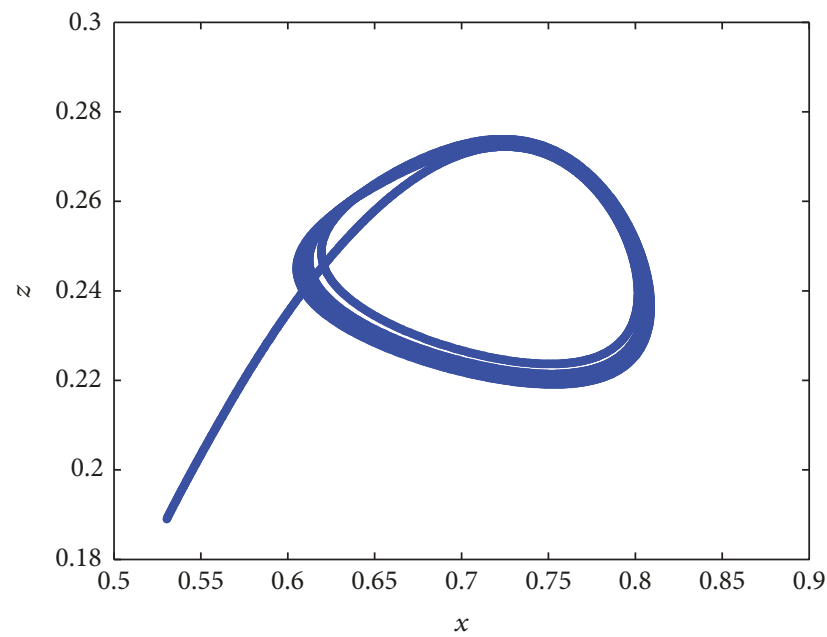

(c) Projection onto the $x-z$ plane when $t_{1}=0.07$

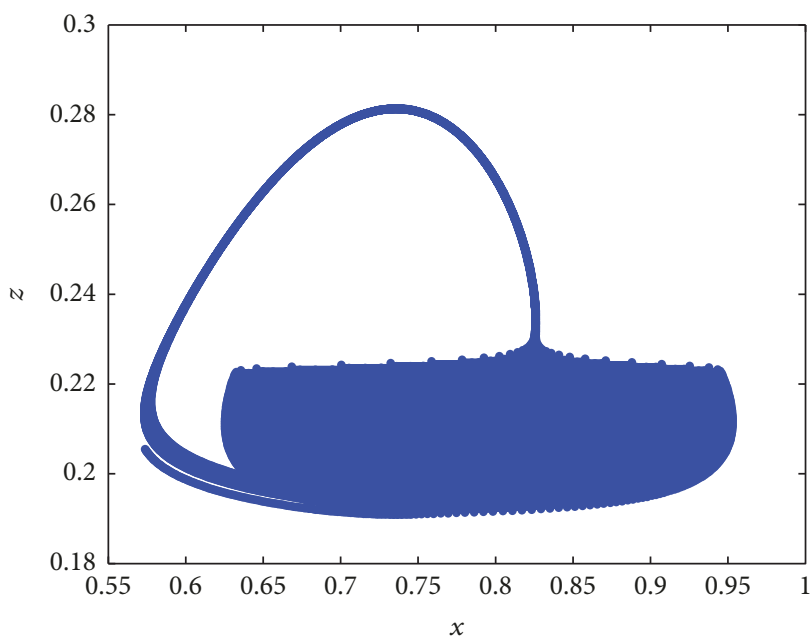

(e) Projection onto the $x-z$ plane when $t_{1}=3.1$

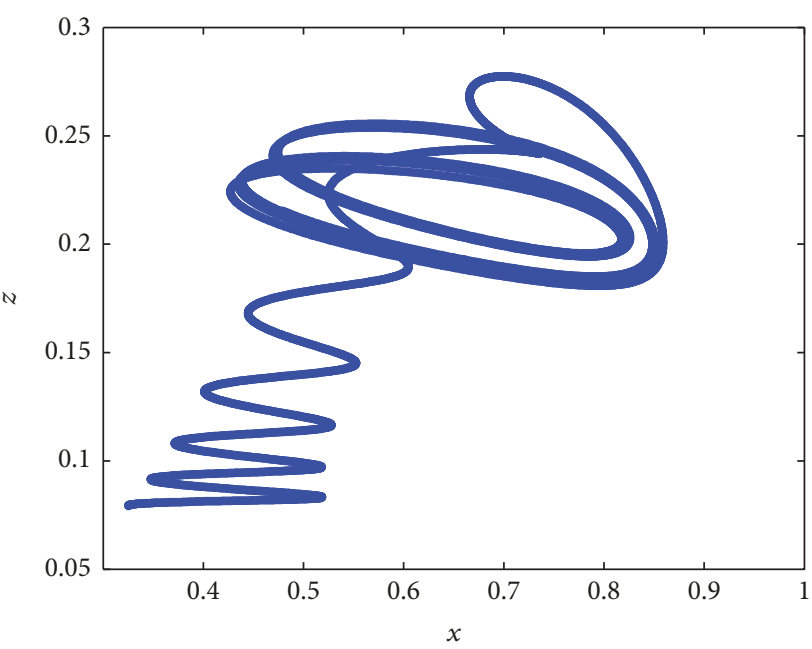

(b) Projection onto the $x-z$ plane when $t_{1}=0.03$

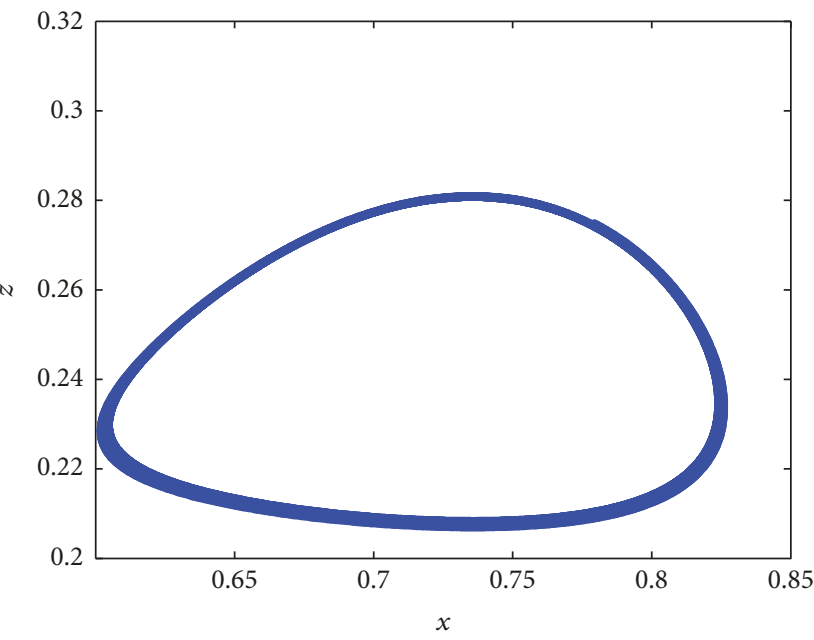

(d) Projection onto the $x-z$ plane when $t_{1}=2.5$

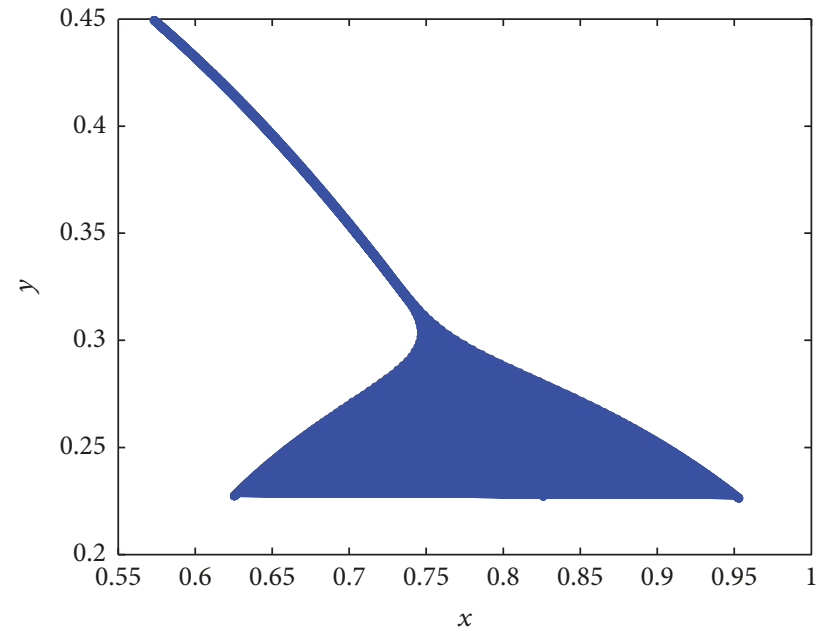

(f) Projection onto the $x-y$ plane when $t_{1}=3.1$

Figure 5: Continued. 


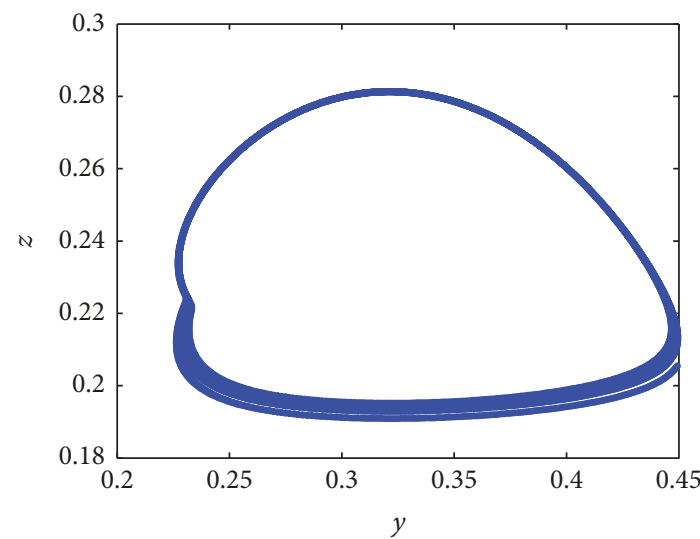

(g) Projection onto the $y-z$ plane when $t_{1}=3.1$

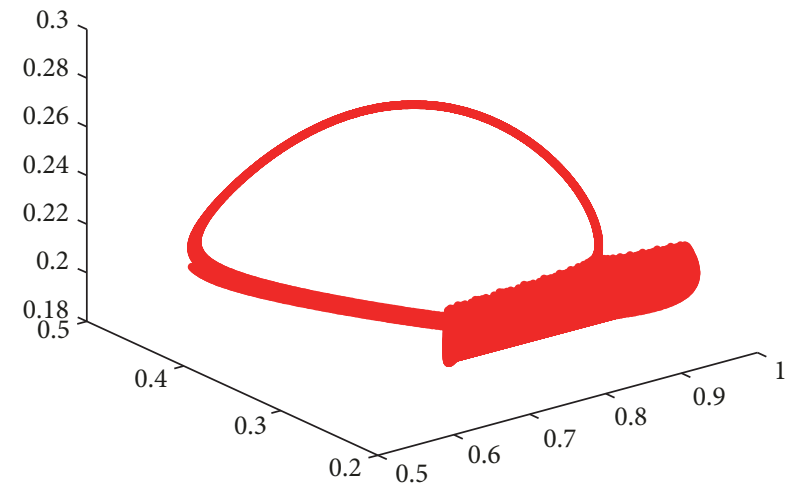

(h) 3D view of attractor in the $x-y-z$ space

FIGURE 5: Phase portraits according to the flip bifurcation diagram with different parameters in the dynamic system in the real estate market when $a=0.44, b=1.14, c=2.93, d=0.54, e=0.21, f=0.1, g=0.35, h=0.2, k=0.25$.

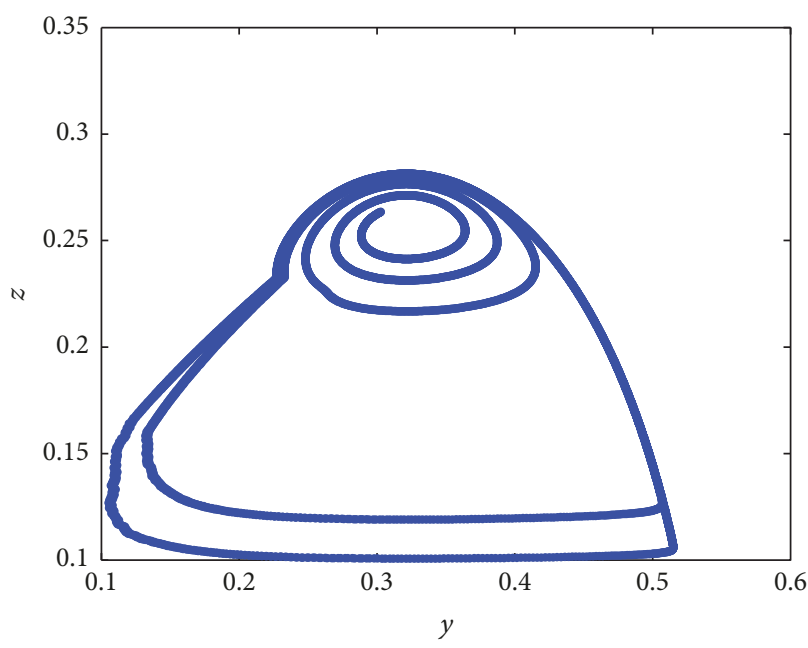

(a) Projection onto the $y-z$ plane

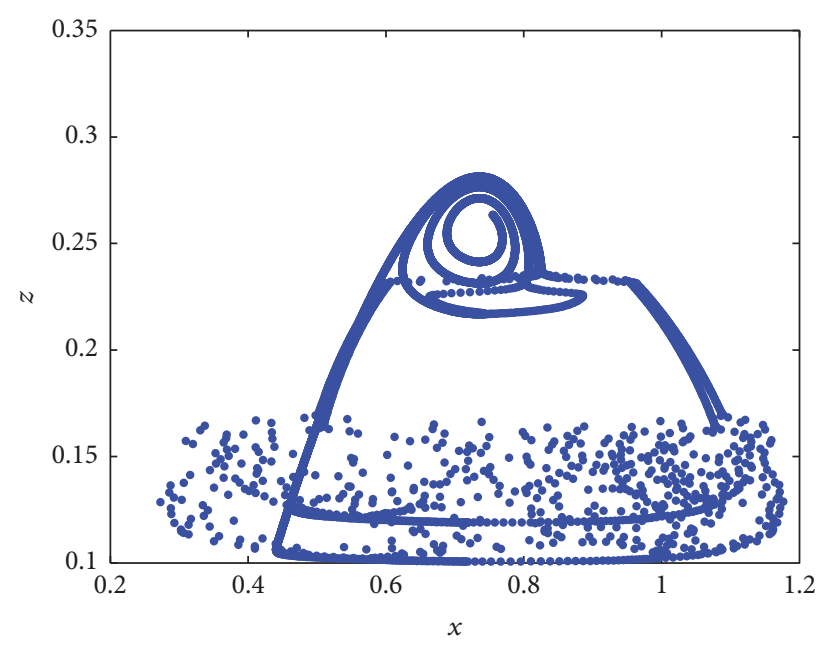

(b) Projection onto the $x-z$ plane

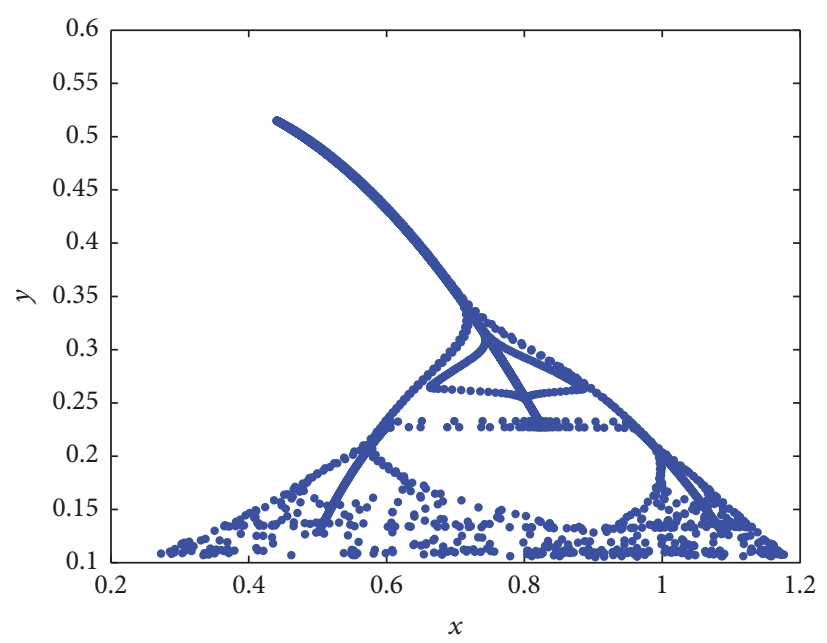

(c) Projection onto the $x-y$ plane

Figure 6: Attractors of dynamic system in the real estate market when $a=0.44, b=1.14, c=2.93, d=0.54, e=0.21, f=0.1, g=$ $0.35, h=0.2, k=0.25$. 


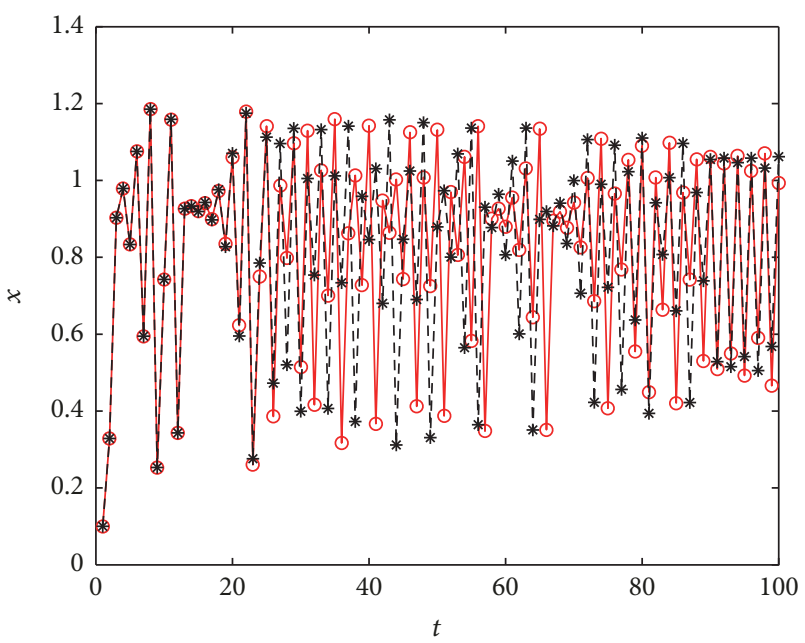

FIGURE 7: Sensitivity analysis for private enterprises in the real estate market when $a=0.44, b=1.14, c=2.93, d=0.54, e=$ $0.21, f=0.1, g=0.35, h=0.2, k=0.25$.

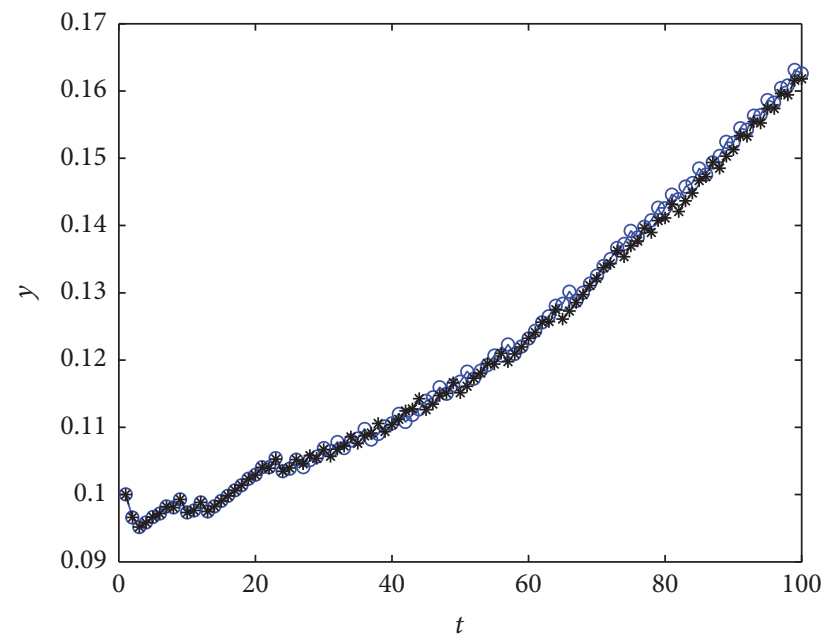

FIGURE 8: Sensitivity analysis for provincial and local officials when $a=0.44, b=1.14, c=2.93, d=0.54, e=0.21, f=0.1, g=$ $0.35, h=0.2, k=0.25$.

$$
\begin{aligned}
& y(t+1) \\
& =y(t) \\
& +\left[-b y(t)+\frac{c x(t) y(t)}{x(t)+d}-\frac{y(t) z(t)}{y(t)+e z(t)+f}\right] \sigma_{2} \\
& z(t+1)=z(t)+\left[g z^{2}(t)-\frac{h z^{2}(t)}{y(t)+k}\right] \sigma_{3}-K z(t) .
\end{aligned}
$$

Figure 14 shows Lyapunov index when parameter $\sigma_{1}$ varies after the addition of control parameter $K$. When $K=0$, the controlled system becomes the original system. From Figure 14, the first Lyapunov exponent is positive; both the second and the third Lyapunov exponents are negative. Therefore, system is in a chaotic state. When $\sigma_{1}=0.548$,

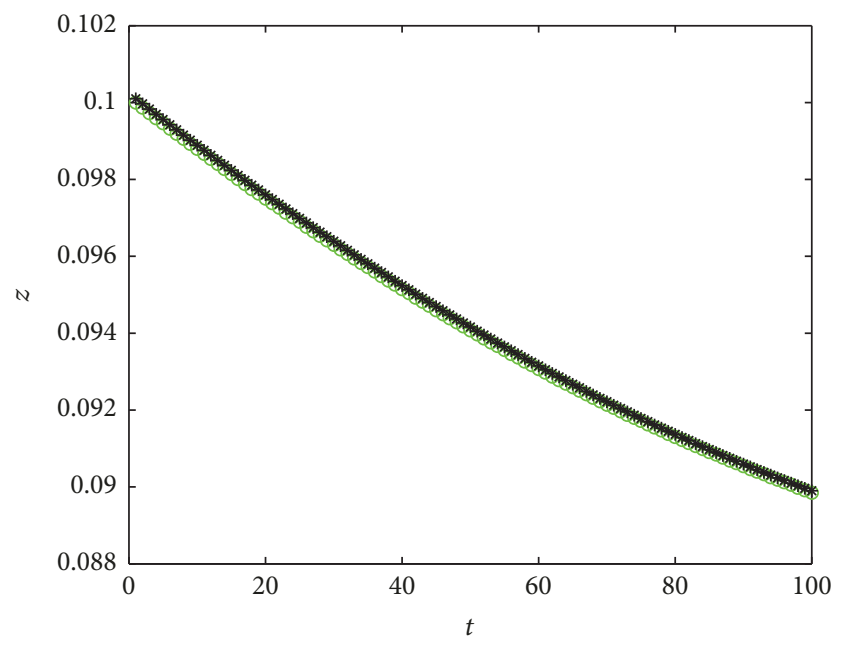

FIGURE 9: Sensitivity analysis for central government when $a=$ $0.44, b=1.14, c=2.93, d=0.54, e=0.21, f=0.1, g=$ $0.35, h=0.2, k=0.25$.

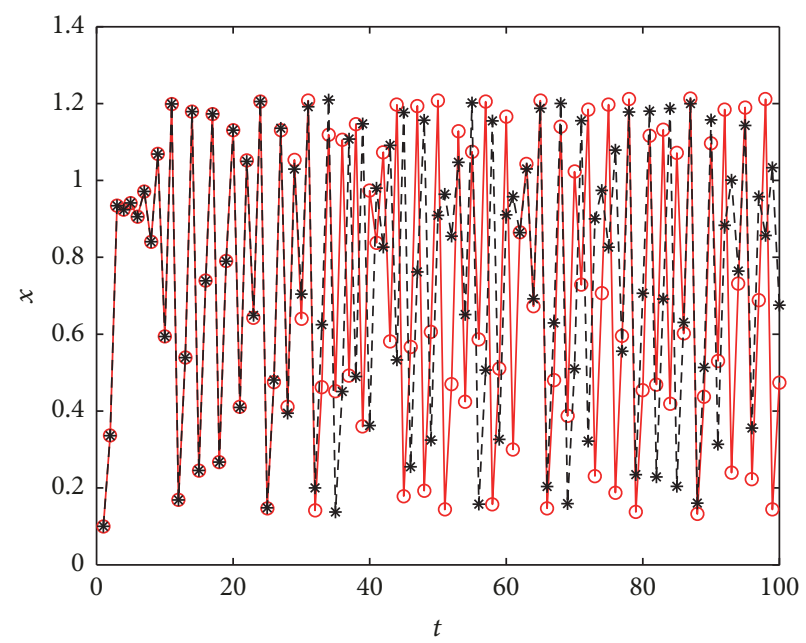

FIgURE 10: Sensitivity analysis for private enterprises in the real estate market when $a=0.44, b=1.14, c=2.93, d=0.54, e=$ $0.21, f=0.1, g=0.35, h=0.2, k=0.25$.

the first Lyapunov exponent is zero, and the system exhibits cycles; when $\sigma_{1}>0.548$, the system is driven to stable state. The evolution in real estate market has been controlled effectively.

Here, $K$ can be considered as the regulation of central government on the market of private enterprises. For instance, the central government can adopt a proper controller parameter $K$ by analyzing the experience or information from past market, and it can also be considered as a learning ability or adaptability or self-protecting ability for private enterprises. For example, there will be a callback because of commercial housing sales being affected by the regulation and control policies of the government. The annual decline will reach $9.3-11.3 \%$, of which the sales in the first-tier cities will remain stable, and the sales in the second-tier cities will decrease significantly. The third-tier cities will also face 


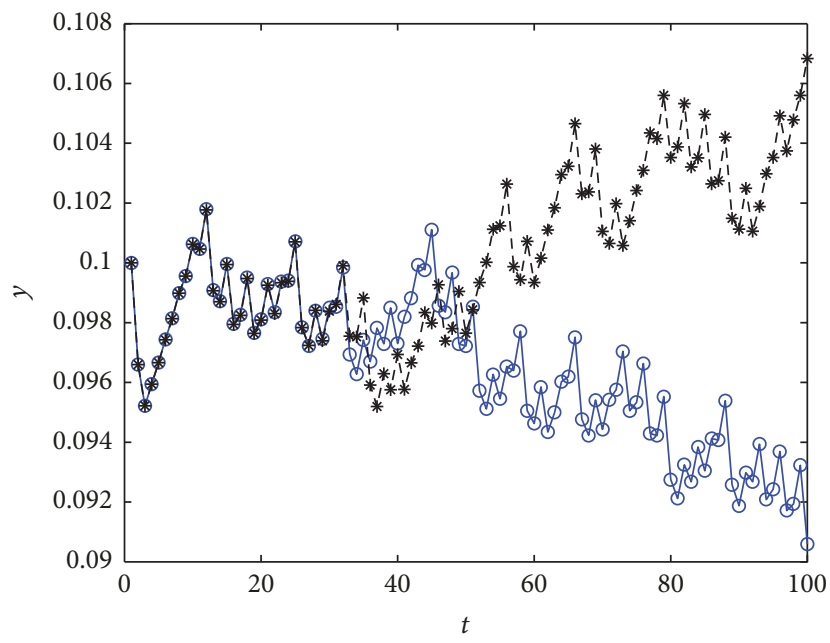

FIGURE 11: Sensitivity analysis for provincial and local officials when $a=0.44, b=1.14, c=2.93, d=0.54, e=0.21, f=0.1, g=$ $0.35, h=0.2, k=0.25$.

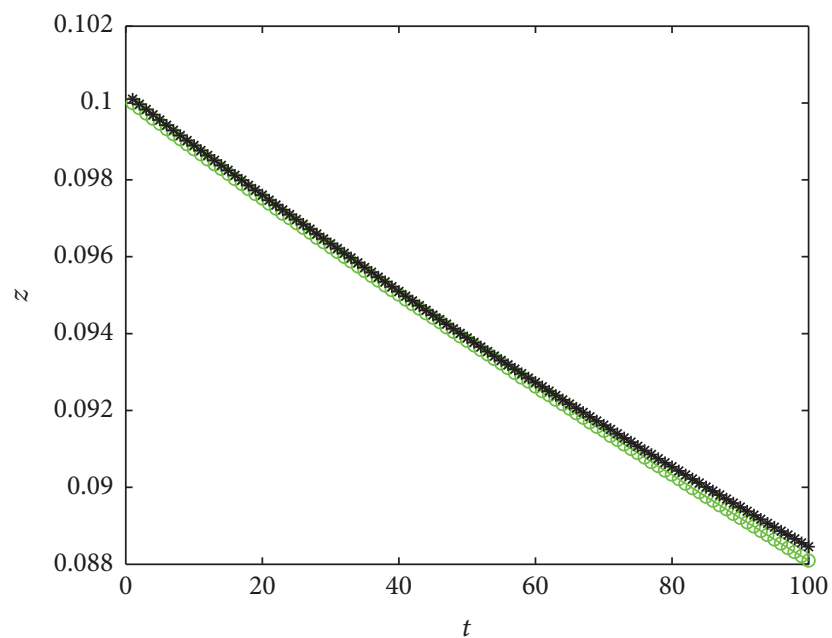

FIGURE 12: Sensitivity analysis for central government when $a=$ $0.44, b=1.14, c=2.93, d=0.54, e=0.21, f=0.1, g=$ $0.35, h=0.2, k=0.25$.

downward pressure on the real estate market after inventory was completed. The private enterprises in real estate market should take measures to cope with such changes in this situation.

\section{Conclusions}

Future policy in real estate market will continue the clear line of "the house is used for living, not for speculation," maintaining the continuity and stability of policy, stabilizing the real estate market, defusing the risk of bubbles, and guiding market expectations.

In this paper, a $3 \mathrm{D}$ continuous dynamic system is proposed and analyzed. Bifurcations and other chaotic phenomena are generated by communication via computing Lyapunov exponents, with Lyapunov dimension showing the

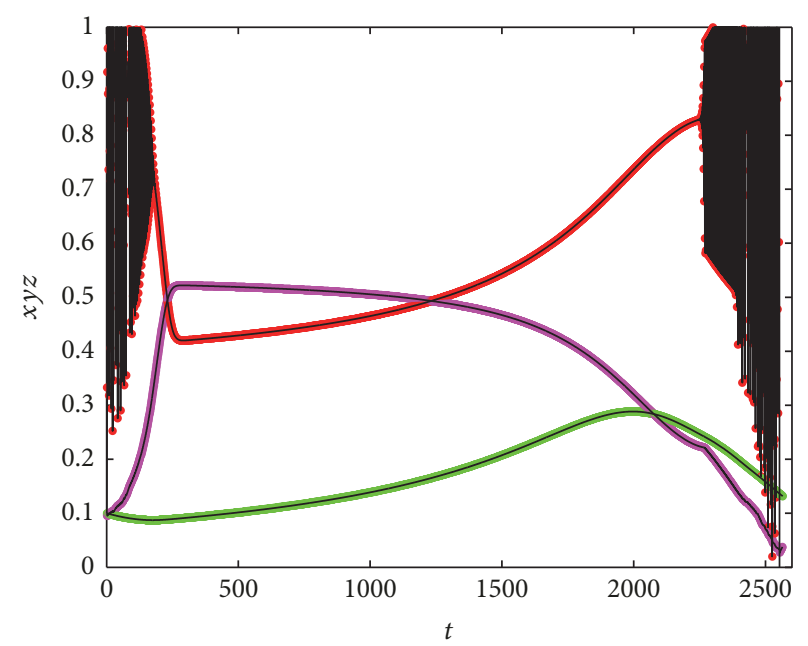

FIGURE 13: Time history figure of the dynamic system in the real estate market.

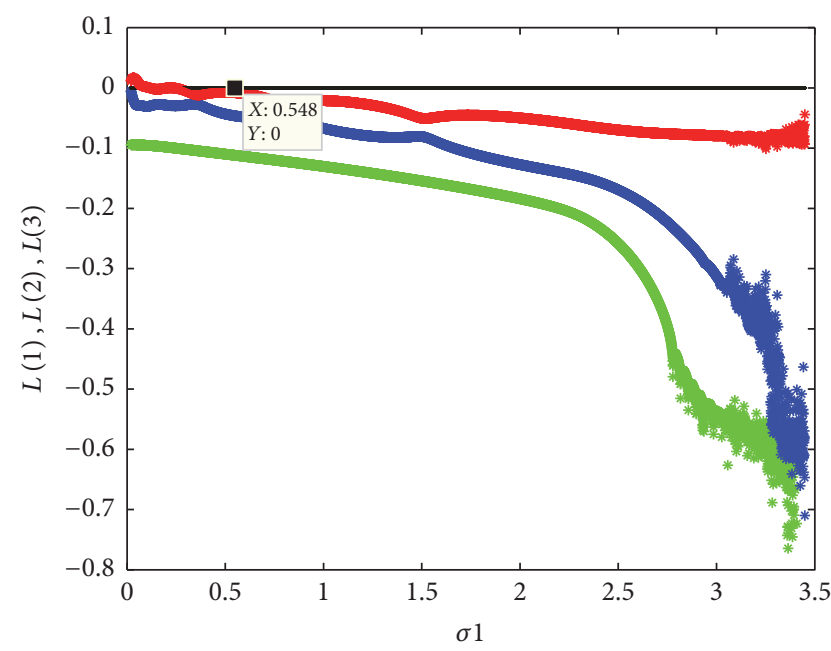

FIGURE 14: Lyapunov index with parameter $K$ of central government.

chaotic attractors, sensitive dependence on initial conditions, and time history figure of the system. Once chaos occurs, the stable state will be broken and the market will become unpredictable, irregular, and abnormal. Finally, a linear feedback control is applied to drive or restore the chaos to be delayed or even eliminated completely, achieving the goal of a steady state.

We can draw some conclusions. (1) Under certain parameters conditions, there are abundant chaotic behaviors in the process of evolution in the real estate market. (2) A suitably evolutionary rate combining with a sufficiently large speed of adjustment parameter results in chaos through flip or Neimark-Sacker bifurcations for the private enterprises and provincial and local officials. Thus, the adjustment parameter takes an essential part in stability of the equilibrium and behavior of the dynamic system. (3) From a macro perspective, the central government should intensify efforts to control, guiding the private enterprises in real estate market, 
and deal with good coordination between the evolution of competition and cooperation. (4) How the chaos affects the three kinds of private enterprises, respectively, in real estate market and what strategies every private enterprise will take to avert risk are the follow-up research contents in this paper.

The implementation of the long-term mechanism will be further accelerated in 2018. At the same time, short-term regulations and long-term mechanisms are linked closely, maintaining the stability of the real estate market and establishing a more stable foundation.

\section{Conflicts of Interest}

The authors declare that they have no conflicts of interest.

\section{Acknowledgments}

(1) Many thanks are given to the National Natural Science Foundation of China (Grants nos. 51379104 and 51579135). (2) This work is supported by the State Key Laboratory of Hydroscience and Engineering (Grants nos. 2013-KY-5 and 2015-KY-5) and Major Science and Technology Research Project of Power China (Grant nos. DJ-ZDZX-2015-01-02, DJ-ZDZX-2015-01-07).

\section{References}

[1] T. Puu, "The chaotic duopolists revisited," Journal of Economic Behavior \& Organization, vol. 33, no. 3-4, pp. 385-394, 1998.

[2] H. N. Agiza and A. A. Elsadany, "Chaotic dynamics in nonlinear duopoly game with heterogeneous players," Applied Mathematics and Computation, vol. 149, no. 3, pp. 843-860, 2004.

[3] H. N. Agiza and A. A. Elsadany, "Nonlinear dynamics in the Cournot duopoly game with heterogeneous players," Physica A: Statistical Mechanics and its Applications, vol. 320, no. 1-4, pp. 512-524, 2003.

[4] H. N. Agiza, E. M. ELabbasy, H. EL-Metwally, and A. A. Elsadany, "Chaotic dynamics of a discrete prey-predator model with Holling type II," Nonlinear Analysis: Real World Applications, vol. 10, no. 1, pp. 116-129, 2009.

[5] J. Ma and X. Pu, "Complex dynamics in nonlinear triopoly market with different expectations," Discrete Dynamics in Nature and Society, vol. 2011, Article ID 902014, 2011.

[6] J. Zhang and J. Ma, "Research on the price game model for four oligarchs with different decision rules and its chaos control," Nonlinear Dynamics, vol. 70, no. 1, pp. 323-334, 2012.

[7] Z. Sun and J. Ma, "Complexity of triopoly price game in Chinese cold rolled steel market," Nonlinear Dynamics, vol. 67, no. 3, pp. 2001-2008, 2012.

[8] P. Yu and X. Liao, "New estimations for globally attractive and positive invariant set of the family of the Lorenz systems," International Journal of Bifurcation and Chaos, vol. 16, no. 11, pp. 3383-3390, 2006.

[9] Z. Wang, J. Ma, Z. Chen, and Q. Zhang, "A new chaotic system with positive topological entropy," Entropy, vol. 17, no. 8, pp. 5561-5579, 2015.

[10] A. A. Elsadany, "Competition analysis of a triopoly game with bounded rationality," Chaos, Solitons \& Fractals, vol. 45, no. 11, pp. 1343-1348, 2012.
[11] A. A. Elsadany, "A dynamic Cournot duopoly model with different strategies," Journal of the Egyptian Mathematical Society, vol. 23, no. 1, pp. 56-61, 2015.

[12] E. Ahmed and H. N. Agiza, "Dynamics of a Cournot game with n-competitors," Chaos, Solitons \& Fractals, vol. 9, no. 9, pp. 15131517, 1998.

[13] M. Zhao and S. Lv, "Chaos in a three-species food chain model with a Beddington-DeAngelis functional response," Chaos, Solitons \& Fractals, vol. 40, no. 5, pp. 2305-2316, 2009.

[14] M. F. Elettreby and S. Z. Hassan, "Dynamical multi-team Cournot game," Chaos, Solitons \& Fractals, vol. 27, no. 3, pp. 666-672, 2006.

[15] M. F. Elettreby and M. Mansour, "On Cournot dynamic multiteam game using incomplete information dynamical system," Applied Mathematics and Computation, vol. 218, no. 21, pp. 10691-10696, 2012.

[16] E. Ahmed, A. M. El-Sayed, and H. A. El-Saka, "Equilibrium points, stability and numerical solutions of fractional-order predator-prey and rabies models," Journal of Mathematical Analysis and Applications, vol. 325, no. 1, pp. 542-553, 2007.

[17] M. F. Elettreby, “Two-prey one-predator model," Chaos, Solitons \& Fractals, vol. 39, no. 5, pp. 2018-2027, 2009.

[18] R. K. Upadhyay, R. K. Naji, S. N. Raw, and B. Dubey, “The role of top predator interference on the dynamics of a food chain model," Communications in Nonlinear Science and Numerical Simulation, vol. 18, no. 3, pp. 757-768, 2013.

[19] M. F. Elettreby and H. El-Metwally, "Multi-team prey-predator model," International Journal of Modern Physics C, vol. 18, no. 10, pp. 1609-1617, 2007.

[20] Y. Liu, Y. Zhao, W. Ren, and G. Chen, "Appointed-time consensus: Accurate and practical designs," Automatica, 2018.

[21] G. Wen, Y. Zhao, Z. Duan, W. Yu, and G. Chen, "Containment of higher-order multi-leader multi-agent systems: a dynamic output approach," Institute of Electrical and Electronics Engineers Transactions on Automatic Control, vol. 61, no. 4, pp. 1135-1140, 2016.

[22] J. Cotter and R. Roll, "A Comparative Anatomy of Residential REITs and Private Real Estate Markets: Returns, Risks and Distributional Characteristics," Real Estate Economics, vol. 43, no. 1, pp. 209-240, 2015.

[23] Z. Y. Mao and X. Y. He, "Distributed finite-time tracking control for the multi-agent systems," Journal of Inner Mongolia University. Natural Science Edition, vol. 47, no. 6, pp. 658-663, 2016.

[24] Y. Zhao, Y. Liu, G. Wen, and G. Chen, “Distributed optimization for linear multiagent systems: edge- and node-based adaptive designs," Institute of Electrical and Electronics Engineers Transactions on Automatic Control, vol. 62, no. 7, pp. 3602-3609, 2017.

[25] Y. Liu, Y. Zhao, and G. Chen, "A decoupled designing approach for sampling consensus of multi-agent systems," International Journal of Robust and Nonlinear Control, 2017.

[26] F. R. Marotto, "Snap-back repellers imply chaos in $R_{n}$," Journal of Mathematical Analysis and Applications, vol. 63, no. 1, pp. 199223, 1978.

[27] H. Zhang and G. Chen, "Single-input multi-output statefeedback chaotification of general discrete systems," International Journal of Bifurcation and Chaos, vol. 14, no. 9, pp. 33173323, 2004. 


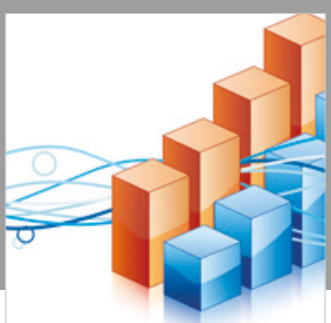

Advances in

Operations Research

\section{-n-m}
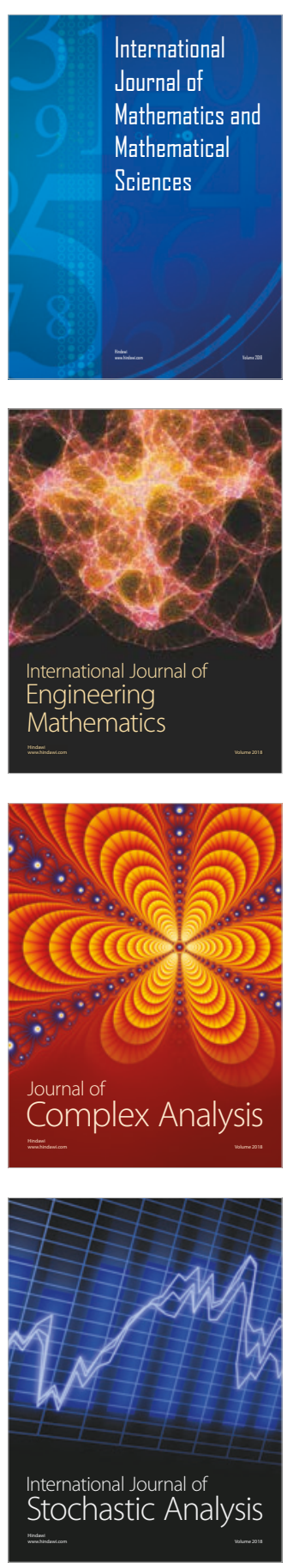
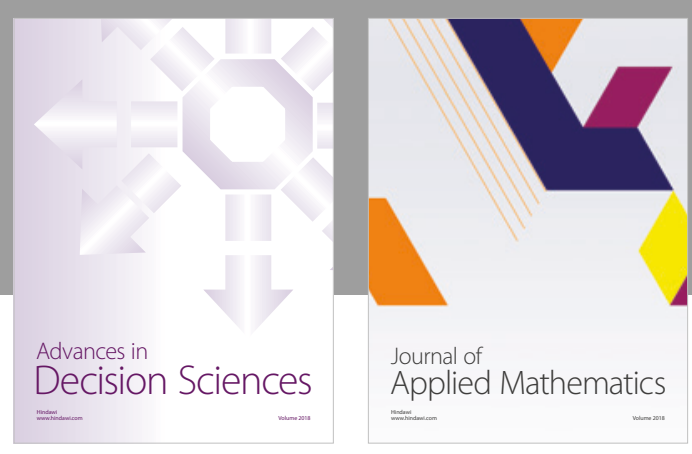

Journal of

Applied Mathematics
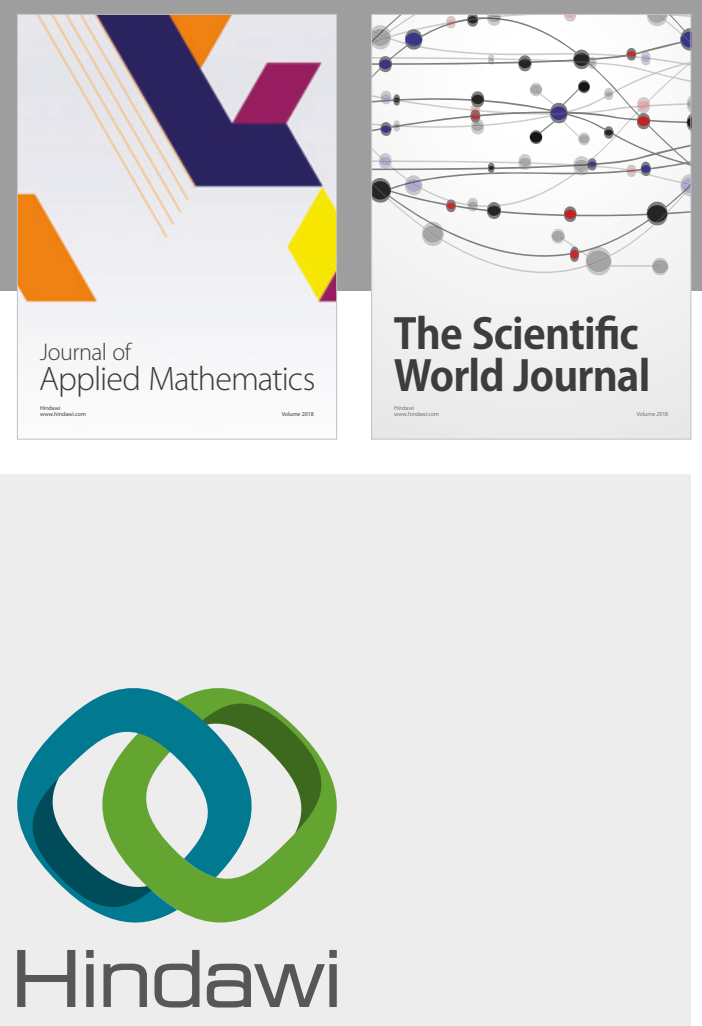

Submit your manuscripts at

www.hindawi.com

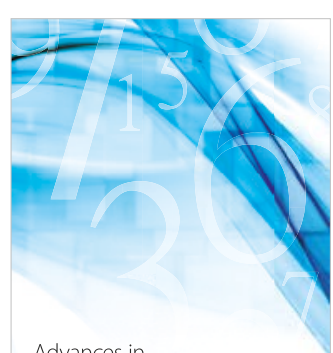

Advances in
Numerical Analysis
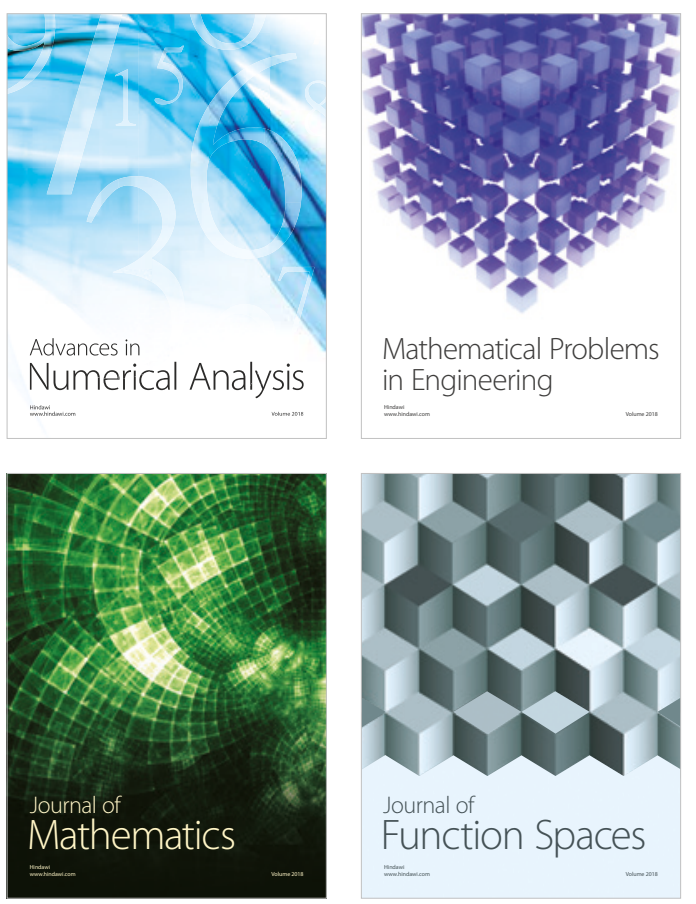

Mathematical Problems in Engineering

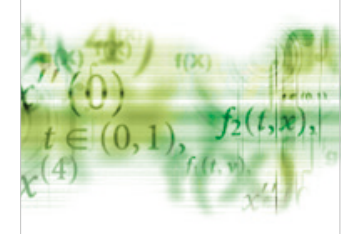

International Journal of

Differential Equations

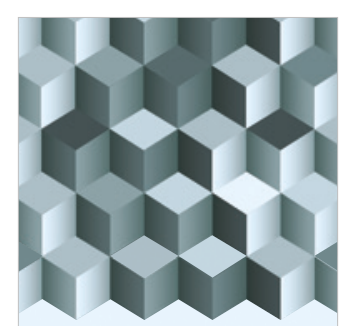

Journal of

Function Spaces
The Scientific

World Journal

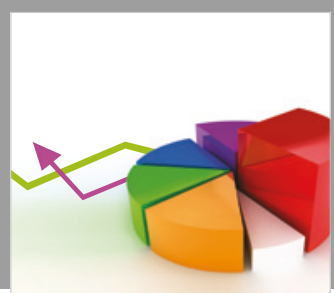

Journal of

Probability and Statistics
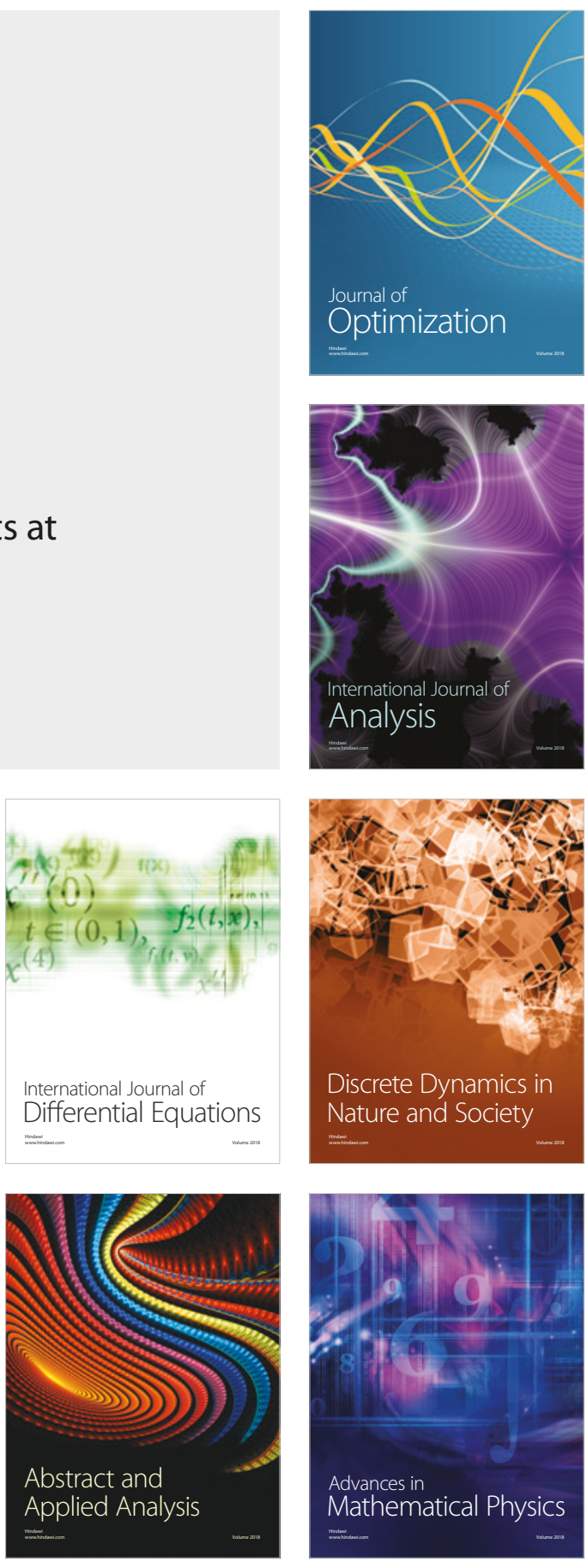